\title{
Artigo de Revisão \\ Produção de biomassa florestal para energia em sistemas agroflorestais
}

\author{
Gabriel Browne de Deus Ribeiro ${ }^{1 \star}$, Crismeire Isbaex ${ }^{1}$, Sebastião Renato Valverde ${ }^{1}$ \\ ${ }^{1}$ Universidade Federal de Viçosa, Av. Purdue, s/nº, Campus Universitário, CEP 36570-900, Viçosa, MG,Brasil
}

"Autor correspondente:

gabrielbrowne@gmail.com

Termos para indexação:

Lenha

Resíduos florestais

Potencial econômico

Index terms:

Wood fuel

Forest residues

Economic potential

Histórico do artigo:

Recebido em 12/12/2016

Aprovado em 05/12/2017

Publicado em 29/12/2017

doi: $10.4336 / 2017 . p f b .37 .92 .1389$

\begin{abstract}
Resumo - O objetivo dessa revisão foi avaliar o potencial da produção de biomassa florestal com fins energéticos em Sistemas Agroflorestais (SAFs). O uso da madeira e de resíduos florestais para energia tem sido bastante estimulado no Brasil e no mundo nas últimas décadas, em razão de questões ambientais e da sua viabilidade técnica e econômica. No entanto, seu desenvolvimento em SAFs ainda necessita de mais estudos. Foram analisadas as principais características técnicas e econômicas para a produção de madeira para energia em SAFs, destacando espécies arbóreas, qualidade de sítio, características socioeconômicas e práticas agrossilviculturais. Os principais estudos encontrados são oriundos da Europa, Estados Unidos, Ásia e África, enquanto que no Brasil ainda existe escassez de trabalhos nesse tema, embora o país seja grande consumidor de biomassa florestal para energia. Todos os trabalhos encontrados indicaram que existe potencial técnico e econômico para a geração de energia de biomassa em SAFs, tanto para o abastecimento do produtor rural, quanto para a comercialização da madeira com qualidade para uso energético. Contudo, essa relação depende fundamentalmente de: maior estruturação do mercado para biomassa florestal, características socioeconômicas regionais e condições ambientais.
\end{abstract}

\section{Forest biomass production for energy in agroforestry systems}

\section{Introdução}

A utilização da biomassa florestal como fonte energética tem sido estimulada nas últimas décadas em razão de aspectos ambientais, econômicos e energéticos. Pelo lado ambiental, existe a necessidade de se mitigar as emissões de gases do efeito estufa, reduzir o consumo de fontes não renováveis e proteger as florestas nativas 
(Fao, 2011; Payn et al., 2015). Pelo aspecto econômico e energético, fatores como as fortes oscilações nos preços dos combustíveis fósseis, a busca por maior segurança energética e o desenvolvimento tecnológico da exploração de recursos renováveis têm incentivado a geração de energia a partir da biomassa florestal oriunda de florestas plantadas (Vital et al., 2013; Zhang et al., 2015).

Para o cenário brasileiro, o crescimento dos plantios florestais e os avanços tecnológicos alcançados no campo da silvicultura (manejo, condução, produtividade, genética, etc.) têm propiciado o uso da biomassa lenhosa como alternativa energética para a geração térmica, cogeração e pequenas centrais elétricas (Brito \& Cintra, 2004). Diversas indústrias e segmentos agropecuários estão optando pela madeira para produção de energia térmica em detrimento dos combustíveis fósseis (Ribeiro \& Valverde, 2016). Segundo Couto \& Muller (2013) a energia de biomassa florestal no Brasil é constituída, em grande parte, pela produção do carvão vegetal (carbonização) e consumo direto da lenha, cavaco e resíduos florestais (combustão).

$\mathrm{Na}$ maior parte dos países em desenvolvimento existe significativa dependência da energia de biomassa florestal, principalmente da lenha e do carvão vegetal (Tabela 1). Estima-se que cerca de 2,7 bilhões de pessoas no mundo são dependentes de combustíveis sólidos, principalmente de madeira para cozimento e aquecimento (Dobie et al., 2015). Em um estudo realizado em dez países africanos, Adkins et al. (2011) observaram que $99 \%$ da população rural utiliza a lenha como fonte primária de energia para cozimento, aquecimento e eletricidade. E tanto a origem quanto a qualidade da madeira são bastante heterogêneas, colhidas normalmente de plantações florestais, sistemas agroflorestais e de florestas pertencentes aos governos.

A lenha é, provavelmente, a fonte energética mais antiga utilizada pelo homem. Segundo dados do Balanço Energético Nacional de 2015, embora seu uso tenha se reduzido no Brasil nos últimos anos em razão da crise do setor siderúrgico nacional, sua participação ainda se destaca na matriz energética brasileira, principalmente nos setores de transformação, industrial, residencial e agropecuário, com cerca de $8 \%$ da produção de energia primária nacional (Empresa de Pesquisa Energética, 2015).

Entretanto, o crescimento dos reflorestamentos dos gêneros Eucalyptus spp. e Pinus spp. também tem gerado maior pressão sobre o uso da terra, acarretando concentração de monocultivos florestais consolidados em grandes produtores, como indústrias de celulose e papel e siderúrgicas, que possuem áreas de plantios acima de 100 mil ha cada (Valverde et al., 2012; Indústria Brasileira de Árvore, 2015). Segundo dados da Indústria Brasileira de Árvores (IBÁ), estima-se que o Brasil possua entre 25 e 30 mil famílias rurais com propriedades de pequeno a médio porte que dependem da agricultura de pequena escala e do uso e produção da madeira, e que, em muitos casos, enfrentam barreiras à competição no mercado de madeira face à sua concentração econômica por parte dos grandes produtores.

Tabela 1. Produção de biomassa florestal para energia, por região, em 2009.

\begin{tabular}{|c|c|c|c|}
\hline Região & Sub-região & $\begin{array}{c}\text { Produção } \\
\left(10^{3} \mathrm{~m}^{3}\right)\end{array}$ & $\begin{array}{c}\text { Região } \\
(\%)\end{array}$ \\
\hline \multirow{5}{*}{ África } & Central & 110.621 & $19 \%$ \\
\hline & Leste & 200.699 & $34 \%$ \\
\hline & Norte & 47.792 & $8 \%$ \\
\hline & Sul & 58.469 & $10 \%$ \\
\hline & Oeste & 171.091 & $29 \%$ \\
\hline Total & & 588.673 & $100 \%$ \\
\hline \multirow{3}{*}{$\begin{array}{c}\text { América Latina e } \\
\text { Caribe }\end{array}$} & Caribe & 5.120 & $2 \%$ \\
\hline & América Central & 40.195 & $17 \%$ \\
\hline & América do Sul & 195.856 & $81 \%$ \\
\hline Total & & 241.171 & $100 \%$ \\
\hline \multirow{4}{*}{ Ásia e Oceania } & Leste Ásia & 216.621 & $27 \%$ \\
\hline & Sul Ásia & 382.745 & $48 \%$ \\
\hline & Sudeste Ásia & 185.903 & $23 \%$ \\
\hline & Oceania & 12.838 & $2 \%$ \\
\hline Total & & 794.104 & $100 \%$ \\
\hline
\end{tabular}

Fonte: Adaptado de Dobie \& Sharma (2014)

Portanto, o emprego da madeira na geração de energia traz grandes desafios para o setor florestal e para as economias rurais. Buscar sistemas de produção florestal que consigam aliar sustentabilidade e produtividade, visando bioenergia, sem marginalizar os pequenos e médios produtores, mas também mitigar os efeitos adversos sobre o meio ambiente, é um importante desafio.

A partir desse ponto de vista, os SAFs podem representar uma alternativa interessante de uso da terra e de produção de madeira para energia, por integrar produção de biomassa e alimentos acessível à agricultura familiar. Diversos estudos na Europa, Estados Unidos, Ásia e África, como os de Rigueiro-Rodríguez et al. 
(2009), Munslow et al. (2012), Montes et al. (2014) e Mirck \& Quinkenstein (2015), demonstram que sistemas agroflorestais, como o Alley Cropping e o Taungya, têm sido desenvolvidos nas últimas décadas com o objetivo principal de produção de madeira para energia. Através da integração da produção arbórea e de cultivos agrícolas, estes sistemas têm demonstrado potencial para oferecer o auto-abastecimento energético em áreas rurais e, também, a diversificação da produção agrícola, focando no fornecimento de biomassa para energia em indústrias locais, integrado à produção de alimentos (Gruenewald et al., 2007).

Utilizando-se práticas agroflorestais, o manejo da produção florestal para uso energético pode auxiliar produtores rurais e comunidades a reduzir o consumo de energia externa, diversificar as fontes de renda e ainda proporcionar benefícios ambientais, conforme apontam estudos do USDA National Agroforestry Center dos Estados Unidos (2012).

Ademais, considera-se que há um grande potencial de mitigação de gases de efeito estufa em sistemas agroflorestais, bem como na redução do uso de madeira de florestas nativas. Com isso, a crescente utilização de biomassa e sua eficiência de conversão para a produção de calor, eletricidade e outros combustíveis pode se tornar um fator significativo na gestão global do $\mathrm{CO}_{2}$ atmosférico nas próximas décadas (Kursten, 2000; Nair et al., 2009).

Assim, este trabalho teve por objetivo revisar e elencar os principais aspectos relacionados à produção de madeira para energia em sistemas agroflorestais, informando sobre: (1) as práticas agroflorestais mais comuns, visando produção de biomassa florestal para energia; (2) as espécies florestais utilizadas para uso energético relatadas em experimentos e suas qualidades energéticas; e (3) as características socioeconômicas e ambientais relacionadas e observadas em regiões com estes modelos de produção. A primeira parte deste estudo focará nas experiências internacionais e, posteriormente, será abordado sobre o Brasil, que ainda possui escassez de estudos sobre o tema, embora seja um grande consumidor de madeira para energia.

\section{Sistemas agroflorestais para produção de madeira para energia}

Os sistemas agroflorestais são definidos como sendo a forma de uso ou manejo integrado da terra onde espécies lenhosas perenes (arbóreas, arbustivas e palmeiras) são utilizadas em associações deliberadas, em uma mesma área, com culturas agrícolas, pastagem e/ou animais, objetivando obter benefícios das interações econômicas, sociais e ambientais resultantes (Nair, 1993; Oliveira Neto et al., 2012; Negash \& Kanninen, 2015). Estes sistemas podem oferecer uma alternativa potencial aos problemas da baixa produtividade, de escassez de alimentos e da degradação florestal e ambiental (Santos \& Paiva, 2002). Além disso, quando estabelecidos e manejados de maneira compatível e adequada às condições ambientais e sociais da localidade, têm o potencial de proporcionar o planejamento de multicultivo para satisfazer demandas da sociedade (Arco-Verde et al., 2009).

Nair (1993) elenca a existência de diversas práticas agrossilviculturais, que variam conforme os objetivos de produção e as condições ecológicas e de mercado local. Para este autor, uma das práticas mais comum é a denominada fuelwood, que consiste na implantação de SAFs voltados para a produção de madeira para energia. Nestes sistemas, as árvores são plantadas em consórcio com a produção agrícola e/ou pecuária, onde o objetivo principal é a produção de madeira como insumo energético, na forma de lenha, resíduos, ou carvão vegetal. As produções agrícola e/ou pecuária servem como fonte de renda complementar, podendo auxiliar na compensação dos custos de implantação florestal e nos períodos de oscilação de preços da madeira.

Os principais SAFs que visam, como objetivo predominante, a produção de madeira para energia são os agrissilviculturais, que são consórcios de espécies arbóreas com cultivos agrícolas. Os sistemas silvipastoris (consórcio de árvores com pastagem e/ ou animais) e os agrissilviculturais (associações de árvores com cultivos agrícolas, pastagem e/ou animais) aparecem em menor proporção quando relacionados a este objetivo. A explicação para que os dois últimos tenham menor inserção é devido à finalidade do sistema. Para que haja produção de madeira para fins energéticos comerciais ou industriais, é importante que o sistema seja manejado para tal fim, enquanto que sistemas associados à pecuária costumam apresentar menor escala para produção madeireira, em função do espaçamento mais amplo, com menor número de árvores por área, dos custos e da maior complexidade de interação entre os componentes do sistema (Jensen, 1995).

Isso não restringe esses dois sistemas para a produção de madeira para energia. Entretanto, é possível que a escala de produção madeireira seja menor, visando 
principalmente o uso da madeira para o abastecimento da propriedade rural e de comércios locais, conforme aponta Jensen (1995).

Desde a década de 1970, diversos estudos foram desenvolvidos abordando a questão da escassez de madeira para energia, com maior ênfase na dificuldade dos países subdesenvolvidos ou em desenvolvimento em obterem essa matéria-prima, tendo em vista dois aspectos: sua dependência de madeira como fonte energética para aquecimento, cocção e outros usos, e o desmatamento de florestas nativas em regiões onde a agricultura exerce maior dominância. A partir disso, o conceito em que relaciona o uso indiscriminado de florestas para energia com o desmatamento de florestas tropicais e a degradação ambiental começou a ser amplamente estudado (Kerkhof, 1990; Mercer \& Soussan, 1992; Nair, 1993). Como consequência, distintos programas foram estabelecidos para estas regiões com o objetivo de se planejar SAFs com prioridade na produção de biomassa para energia, bem como identificar as características necessárias para o sucesso destes sistemas (estudos de espécies arbóreas para energia, tratos silviculturais, espécies agrícolas com boa adaptabilidade e aspectos econômicos).

Entretanto, Gregerson et al. (1989), Nair (1993) e Munslow et al. (2012) entendem que, nos países subdesenvolvidos e em desenvolvimento, a prioridade dos agricultores não é exclusivamente a produção de madeira para energia, mas sim a composição de multiprodutos florestais e agropecuários inseridos na cultura local e, sobretudo, com potencial de comercialização. Além disso, também apontam que, embora a maior parte da demanda de lenha esteja associada ao consumo das famílias rurais, uma das formas de se reduzir a escassez de lenha seria através do maior incentivo aos agricultores a plantar árvores suficientes para satisfazer as suas próprias necessidades e gerar excedentes para venda. Nesse aspecto, sugerem que, a depender do grau de desenvolvimento econômico e tecnológico da região, o plantio florestal energético deve ser visto como um benefício secundário, e não como o principal objetivo do sistema.

Neste sentido, Nair (1993) levanta as seguintes questões sobre a prática de SAFs para energia de biomassa: i) produtores rurais raramente compartilham das preocupações das Agências Governamentais sobre as crises de escassez de lenha; ii) embora exista um grande potencial para aumentar a produção de lenha através de
SAFs, para que tais iniciativas sejam bem sucedidas, a produção de madeira para energia deve ser promovida como um benefício secundário, e não como produto final exclusivo; e iii) pequenos agricultores e comunidades locais possuem maior propensão a escolher espécies arbóreas localmente adaptadas, com comprovado potencial de geração de renda e que produzem vários produtos, ao invés daquelas que fornecem apenas madeira para energia.

Neste aspecto, se observa que a condição básica para o sucesso econômico dos sistemas de produção de madeira para energia é a existência de mercado local para tais produtos (lenha, carvão vegetal, resíduos, cavaco) e a competição em relação aos demais usos da madeira na região e no meio rural (Kursten, 2000).

Munslow et al. (2012) elencam, dentro dessa linha, os principais fatores que afetam a disponibilidade da energia de biomassa florestal para determinada região (Tabela 2).

Tabela 2. Fatores que afetam a disponibilidade de biomassa florestal para energia.

\begin{tabular}{cc}
\hline Disponibilidade de biomassa florestal por sistema de uso da terra \\
\hline $\begin{array}{c}\text { Potencial ambiental/ } \\
\text { ecológico }\end{array}$ & Clima \\
& Topografia \\
Solo
\end{tabular}

Continua... 
Tabela 2. Continuação.

\begin{tabular}{c}
\hline Distribuição da terra \\
Competição com a agropecuária \\
Diferenciação social e cultural \\
Acesso social $\quad \begin{array}{c}\text { Acesso ao mercado } \\
\text { Políticas governamentais (florestais e } \\
\text { energéticas) }\end{array}$ \\
\hline Fonte: Adaptado de Munslow et al. (2012).
\end{tabular}

\section{Sistemas agrissilviculturais - Taungya}

Os SAFs mais comuns relatados na literatura associados à produção de madeira para energia são os sistemas Taungya e Alley Cropping. No sistema denominado Taungya, os cultivos agrícolas anuais são plantados nas entrelinhas durante os primeiros anos de estabelecimento dos plantios florestais. A rentabilidade da produção agrícola (alimentos, forragem, etc.) representa uma antecipação de receitas, podendo reduzir ou até compensar os custos iniciais do reflorestamento (Platen, 1996; Kalame et al., 2011) e, portanto, fornecer incentivos para o plantio de árvores nas propriedades rurais (Schlönvoigt \& Beer, 2001). Além disso, como o objetivo principal deste sistema é a produção de madeira, costuma-se implantar operações de plantio e manejo silvicultural adequado às plantações florestais, tais como: i) utilização de espaçamentos tradicionais de monocultivos florestais, com o objetivo de elevar o número de árvores por área, variando normalmente de 6 a $12 \mathrm{~m}^{2}$ de área útil por planta; ii) cortes culturais, desramas, desbastes, reforma; e iii) preparo do solo e fertilização.

Exemplos de Taungya voltados para produção de madeira para energia têm sido mais encontrados na América do Norte e Central, Ásia, e países da África (Kursten, 2000; Kalame et al., 2011; Kalu et al., 2011). No Brasil também tem crescido a quantidade de sistemas Taungya com essa finalidade.

$\mathrm{Na}$ América Central, principalmente na Costa Rica, a implantação de SAFs do tipo Taungya tem sido estimulada pelo mercado de madeira para energia, com a substituição de combustíveis fósseis pela lenha em pequenas indústrias (Portilla \& Mckenzie, 1991; Kursten, 2000). Com um mercado ávido por lenha, a produção florestal pode ser manejada para maior qualidade energética, assim como ser planejada para multiprodutos florestais (lenha, carvão vegetal, madeira para serraria ou para construção). Em adição, a produção agrícola do sistema Taungya tem potencial para reduzir os custos de implantação do reflorestamento.

Em um estudo em El Salvador, Kursten (2000) aponta os benefícios econômicos de um SAF do tipo Taungya com eucalipto manejado para energia (lenha), consorciado com o cultivo de milho nos primeiros quatro anos. Segundo o autor, comparando-se a lucratividade dos monocultivos de eucalipto, de milho e do SAF (eucalipto e milho), observou-se que: o SAF obteve maior receita líquida; a produção dos componentes não foi afetada pela interação entre eles; a receita do milho nos primeiros anos foi capaz de reduzir os custos de estabelecimento e de manutenção do eucalipto; e conseguiu-se produzir madeira com qualidade para energia (Tabela 3 ).

Redhead \& Maghembe (1982) e Kalu et al. (2011), por outro lado, observaram que as culturas agrícolas alimentares costumam obter melhor produtividade no primeiro ano de consórcio com a espécie arbórea, com gradativa redução no segundo e nos anos subsequentes, em razão do progressivo fechamento da copa da cultura arbórea, acarretando menor irradiância sobre o componente agrícola e afetando seu desenvolvimento em longo prazo.

Na Nigéria e nos países da África Subsaariana outros estudos também confirmaram o potencial do sistema Taungya para produção de biomassa florestal para energia. Kalu et al. (2011) demonstraram que no estado de Edo, na Nigéria, em praticamente 100\% dos sistemas Taungya pesquisados houve rentabilidade da produção de lenha associada às culturas agrícolas. Em adição, também se observou que estes sistemas possuem importante papel na região, uma vez que conseguem abastecer os mercados locais com produtos florestais não madeireiros (PFNM). Espécies arbóreas como Tectona grandis e Eucalyptus spp. são bastante apreciadas nessas regiões para o sistema Taungya, enquanto que algumas leguminosas como o feijão também têm obtido bom rendimento em associações. 
Tabela 3. Receita líquida de diferentes sistemas em El Salvador.

\begin{tabular}{ccccccc}
\hline Tipo de sistema & & & & & $\begin{array}{c}\text { Receita } \\
\text { Líquida } \\
\text { Total }\end{array}$ \\
\hline Milho (monocultivo) & & $\mathbf{1}^{\mathbf{0}}$ ano & $\mathbf{2}^{\mathbf{0}}$ ano & $\mathbf{3}^{\mathbf{0}}$ ano & $\mathbf{4}^{\mathbf{0}}$ ano & \\
Custos (-) & Mão de obra & $2.104,78$ & $2.104,78$ & $2.104,78$ & $2.104,78$ & \\
& Insumos & 808,02 & 808,02 & 808,02 & 808,02 & \\
Receita bruta (+) & & $5.916,00$ & $5.916,00$ & $5.916,00$ & $5.916,00$ & \\
Receita líquida & & $3.003,20$ & $3.003,20$ & $3.003,20$ & $3.003,20$ & $12.012,80$ \\
\hline Eucalipto (monocultivo) & & & & & & \\
Custos (-) & Mão de obra & $1.837,38$ & 469,21 & 413,51 & $3.431,61$ & \\
Receita bruta (+) & Insumos & $1.012,21$ & 58,21 & 58,21 & 58,21 & \\
Receita líquida & & 0,00 & 0,00 & 0,00 & $25.145,03$ & \\
SAF (eucalipto + milho) & & $-2.849,59$ & $-527,41$ & $-471,71$ & $21.655,21$ & $17.806,50$ \\
Custos (-) & Mão de obra & $3.083,73$ & $1.914,94$ & 390,84 & $3.843,89$ & \\
& Insumos & $2.275,31$ & 766,31 & 120,85 & 120,85 & \\
Receita bruta (+) & & $4.102,80$ & $4.102,80$ & 0,00 & $24.869,09$ & \\
Receita líquida & & $-1.256,24$ & $1.421,53$ & $-511,69$ & $20.904,31$ & $20.557,92$ \\
\hline
\end{tabular}

Valores em Colones ha-1 ${ }^{-1}$ em 1991. Fonte: Kursten (2000).

\section{Sistemas agrissilviculturais - Alley Cropping}

O SAF Alley Cropping é caracterizado por fileiras densas de cultivos agrícolas, plantadas com espécies arbóreas ou arbustivas, geralmente fixadoras de nitrogênio, como leguminosas e espécies de rápido crescimento (Giwa et al., 2017). Exemplos do SAF Alley Cropping para produção de energia de biomassa florestal podem ser encontrados principalmente na Europa, em países como Alemanha, Inglaterra, Irlanda, França, Espanha e alguns países da Europa Central e, também, na África e Ásia (Rigueiro-Rodríguez et al., 2009).

AAlemanha tem sido pioneira no estudo deste sistema, através do Agforward Research Project, programa da União Europeia que visa a promoção de práticas agroflorestais na região, buscando desenvolver maior sustentabilidade rural e avaliar inovações em desenhos e tecnologias para SAFs (Mirck \& Quinkenstein, 2015).

Em um experimento desse programa, se implantou na Alemanha sistemas Alley Cropping com a integração de fileiras de espécies arbóreas de crescimento rápido e fixadoras de nitrogênio, que foram o populus (Populus spp.) e a acácia (Robinia pseudoacacia), com cultivos agrícolas: beterraba, cevada, milho e batata em arranjos espaciais densos, com mais de 8.000 árvores $\mathrm{ha}^{-1}$. O objetivo desse experimento foi estudar o comportamento e desenvolvimento dos cultivos florestais e agrícolas em conjunto, e avaliar o potencial de biomassa gerada para energia. Os principais resultados demonstraram que para as espécies arbóreas houve elevada produtividade de madeira com potencial energético, sendo recomendadas podas regulares nas leguminosas, para a incorporação de biomassa ao solo, além da utilização dos próprios resíduos como lenha; observaram-se melhorias nas qualidades físicas, químicas e biológicas do solo, com maior ciclagem de nutrientes e fixação biológica de nitrogênio; a produtividade média anual das culturas agrícolas tem sido bastante parecida com os resultados obtidos em monocultivos agrícolas para estas regiões na Alemanha, o que comprova que a competição entre os cultivos arbóreos e agrícolas pouco afetou o desempenho produtivo. No entanto, o estudo aponta que os custos de estabelecimento, manutenção dos sistemas, a escolha das espécies, do espaçamento e os resultados financeiros em longo prazo ainda podem trazer dificuldades à implantação desses sistemas (Mirck \& Quinkenstein, 2015; AgroForstEnergie, 2015).

Nesse aspecto, segundo Gruenewald et al. (2007), ainda há falta de conhecimento sobre a seleção de espécies arbóreas para estes sistemas. Principalmente ao se pensar na sustentabilidade da produção de diferentes espécies arbóreas de crescimento rápido em condições desfavoráveis, ou sub-ótimas para a produção arbórea, 
tais como solos de baixa fertilidade e elevado déficit hídrico.

Diante disso, Gruenewald et al. (2007) realizaram dois experimentos na Alemanha com SAFs Alley Cropping em áreas marginais, sob condições desfavoráveis de solo e balanço hídrico. Foram estudadas a produtividade e a sustentabilidade da produção para diferentes clones de Populus spp., Salix viminalis e Robinia pseudoacacia, considerando diferentes períodos de rotação e variações nas práticas de adubação. Segundo os autores, os maiores rendimentos de biomassa lenhosa foram encontrados em $R$. pseudoacacia, independente do período de rotação e das práticas de melhoramento do solo. Em relação à interação entre as árvores e o componente agrícola implantado (alfafa, Medicago sativa), praticamente não houve influência negativa sobre a produtividade de ambos. Outra análise importante deste estudo foi o poder calorífico das espécies arbóreas. O cavaco produzido de $R$. Pseudoacacia apresentou maior poder calorífico do que das outras espécies, demonstrando o potencial energético dessa espécie em sistemas Alley Cropping na região em estudo.

Munslow et al. (2012) citam experiências na Nigéria e alguns países da África Subsaariana com a implantação de sistemas Alley Cropping com a combinação de Leucaena leucocephala (leucena) e milho. O manejo destes sistemas para energia é feito principalmente através das podas constantes da leucena, deixando-se a folhagem no solo como adubação verde, e os galhos e ramos, que apresentam alto poder calorífico, são removidos para uso energético. Os resultados dessas experiências, segundo os autores, mostraram que: a produtividade do milho foi elevada; houve grande produção de massa seca para energia e houve aumento gradual do conteúdo de matéria orgânica do solo, se traduzindo em melhora na fertilidade do solo, nas suas propriedades químicas e físicas e na redução da erosão eólica e hídrica com a melhoria nas taxas de infiltração. No entanto, os autores concluem que a maior necessidade de mão de obra para o sistema pode ser considerado um fator desencorajador, sobretudo em áreas com maior escassez de trabalhadores e menor disponibilidade de capital.

Em Ruanda (África), Ndayambaje \& Mohren (2011) apontam que há significativa dependência de madeira para energia no país, onde mais de $85 \%$ da população consome madeira para cozimento e iluminação, além de sua importância para fornecer energia para pequenas indústrias e instituições públicas. As espécies de eucalipto são responsáveis por mais de $65 \%$ dos plantios florestais em Ruanda, em função de seu rápido crescimento, capacidade de rebrota, e adaptabilidade a diferentes tipos de solo e clima, sendo bastante utilizadas em monocultivos e SAFs.

Em relação ao sistema Alley Cropping em Ruanda, Ndayambaje \& Mohren (2011) citam que existem diversas experiências promissoras no país, em razão das condições topográficas e da baixa qualidade e escassez de terras na região. Também comentam sobre a importância das podas periódicas em espécies leguminosas fixadoras de nitrogênio, o que contribui fortemente para evitar o sombreamento, reduzir a competição por água e nutrientes, e ainda para fornecer adubo verde para as culturas agrícolas associadas. As principais espécies arbóreas referidas nesses sistemas são: Gliricidia sepium, Flemingia macrophilla, Mimosa scabrella, Grevillea robusta, Erythrina abyssinica e Dracaena afromontana.

\section{Sistemas agrissilvipastoris}

Jensen (1995) realizou extenso levantamento sobre a capacidade de produção de lenha e carvão vegetal em SAFs de diversos países asiáticos. Os principais resultados encontrados demonstram que a maioria dos sistemas agroflorestais na Ásia não são implantados com o principal propósito de fornecer madeira, tendo em vista que conseguem produzir, em escala satisfatória, forrageiras, cereais, leguminosas, e vários produtos de origem animal. Grande parte da madeira produzida nos SAFs asiáticos é direcionada para multiprodutos, abastecendo a propriedade rural com lenha, estacas, moirões, forragem e o excedente vendido em comércio local. Outros pontos importantes relatados neste estudo fazem referência à grande variação de sistemas encontrados, representando uma ampla gama de situações. Pode-se citar: i) em relação à densidade de árvores: variando de sistemas como o Alley Cropping, com 50 mil árvores ha-1 ${ }^{-1}$ e agrissilvipastoris/ silvipastoris com árvores espalhadas ou dispersas em pastagens, com 60 a 500 árvores ha ${ }^{-1}$; ii) com relação à produtividade do componente arbóreo por região: mais elevada nas regiões úmidas asiáticas, por meio de sistemas que utilizam árvores de rápido crescimento, como Leucaena leucocephala e Calliandra calothyrsus, em altas densidades de até 40.000 árvores ha $^{-1}$, e por outro lado, baixa produtividade em áreas sub-úmidas da Ásia, principalmente em sistemas agrissilvipastoris 
e silvipastoris, com menor densidade de árvores ha ${ }^{-1}$; iii) com relação à produção anual de biomassa para energia: além de ser maior nas regiões úmidas, também menciona melhor produtividade em sistemas agrissilviculturais, onde não há a presença de pastagens e/ou animais (em média: $27 \mathrm{~kg}$ árvore ${ }^{-1}$ ano $^{-1}$ de biomassa para energia em sistemas agrissilviculturais nas regiões de clima úmido; e $8,4 \mathrm{~kg}$ árvore ${ }^{-1}$ ano $^{-1}$ de biomassa para energia em sistemas silvipastoris nas regiões de clima sub-úmido).

Portanto, a menor produtividade de madeira e reduzida produção de biomassa para energia encontrada em sistemas agrissilvipastoris e silvipastoris levam a crer que a disponibilidade de biomassa florestal para energia depende bastante do objetivo do sistema. Além disso, demais fatores que influenciam a oferta de madeira para energia nestes sistemas são: condições ambientais; produtividade da espécie arbórea; manejo agroflorestal; fatores socioeconômicos; infraestrutura e distribuição/ logística; políticas e legislação.

\section{Espécies arbóreas com qualidade para produção de energia em SAFs}

De modo geral, as principais características requeridas das espécies arbóreas para os SAFs que produzem madeira para energia (fuelwood) são: i) potencial energético, isto é, maior densidade energética, poder calorífico e produção de biomassa seca de madeira, conferindo-as potencial para uso em cozimento, aquecimento, iluminação e insumo para carvão vegetal; ii) potencial para outros usos que não a energia, tais como serraria, construção rural, quebra-ventos, cerca viva, ciclagem de nutrientes; iii) que sejam de fácil estabelecimento e adaptação às condições climáticas locais, de rápido crescimento e que necessitem de tratos menos complexos; iv) que possuam capacidade para fixação biológica de nitrogênio e de rebrota das cepas; e v) que apresentem combustão sem gases tóxicos e baixo teor de cinzas ( Nair, 1993; Vidal \& Hora, 2010; Munslow et al., 2012; Montes et al., 2014).

Para Vital et al. (2013), a qualidade da madeira é uma combinação de características físicas, químicas, anatômicas e térmicas de uma árvore, que permitem sua melhor aplicação em determinado uso final. As principais propriedades da biomassa para energia relatadas na literatura são: densidade da madeira, poder calorífico, umidade, característica química elementar, imediata e estrutural, teor de inorgânicos e o comportamento térmico da biomassa.

Outro fator importante, de acordo com Vidal \& Hora (2010), é a eficiência energética da queima da madeira, que depende basicamente do sistema de conversão empregado e do nível de tecnologia e capital do seu produtor. Segundo a FAO (2008), em uso residencial, a queima direta em fornos simples converte apenas 5\% do potencial energético da madeira. Em sistemas de fornos tradicionais convertem $36 \%$, sendo que a produção de carvão vegetal tem eficiência entre $44 \%$ e $80 \%$. Os modernos fornos de pellet apresentam $80 \%$ de eficiência em usos residenciais, mais utilizados nos países desenvolvidos devido ao elevado preço de aquisição.

Por mais que o conhecimento das características energéticas abordadas seja fundamental para a escolha da espécie arbórea visando produção de energia, se observa que em muitas regiões, e principalmente aquelas com menor grau de desenvolvimento socioeconômico, a escolha da espécie é baseada no conhecimento empírico do potencial da madeira, e na sua aceitação como fonte de renda em mercados locais. A tabela 4 resume as principais espécies arbóreas encontradas na literatura relacionadas ao uso energético.

Tabela 4. Principais espécies arbóreas associadas à produção de energia em SAFs.

\begin{tabular}{|c|c|c|c|c|}
\hline Espécie arbórea & Local & Tipo de SAF & Componente associado & Autor (es) \\
\hline Robinia pseudoacacia & Alemanha & Alley Cropping & Alfafa & Gruenewald et al. (2007) \\
\hline $\begin{array}{l}\text { R. pseudoacacia } \\
\text { Poplar spp. }\end{array}$ & Alemanha & Alley Cropping & Beterraba, cevada, milho, batata & Mirck \& Quinkenstein (2015) \\
\hline Leucaena leucocephala & Nigéria & Alley Cropping & Milho & Munslow et at. (2012) \\
\hline $\begin{array}{l}\text { Gliricidia sepium } \\
\text { Mimosa scabrella }\end{array}$ & & & & \\
\hline $\begin{array}{l}\text { Grevillea robusta } \\
\text { Erythrina abyssinica } \\
\text { Dracaena afromontana }\end{array}$ & Ruanda & Alley Cropping & Leguminosas & Ndayambaje \& Mohren (2011) \\
\hline
\end{tabular}


Tabela 4. continuação.

\begin{tabular}{|c|c|c|c|c|}
\hline Espécie arbórea & Local & Tipo de SAF & Componente associado & Autor (es) \\
\hline $\begin{array}{l}\text { L. leucocephala Calliandra } \\
\text { calothyrsus }\end{array}$ & Ásia & Alley Cropping & Leguminosas & Jensen (1995) \\
\hline Eucalyptus spp. & El Salvador & Taungya & Milho & Kursten (2000) \\
\hline $\begin{array}{l}\text { Eucalyptus spp. } \\
\text { Tectona grandis }\end{array}$ & Nigéria / SADC & Taungya & Feijão & Kalu et al. (2011) \\
\hline $\begin{array}{l}\text { Eucalyptus spp. } \\
\text { Pinus spp. }\end{array}$ & Ruanda & Agrissilviculturais & Diversos agrícolas & Ndayambaje \& Mohren (2011) \\
\hline Eucalyptus spp. & Brasil & Taungya & Milho, feijão, arroz & Rodigheri et al. (2001) \\
\hline $\begin{array}{l}\text { Acacia mangium } \\
\text { A. auriculiformis }\end{array}$ & Brasil & Agrissilviculturais & Diversos agrícolas & $\begin{array}{l}\text { Azevedo et al. (2002); Souza } \\
\text { et al. (2008) }\end{array}$ \\
\hline E. urophylla $x$ E. grandis & Brasil & Agrossilviculturais & Feijão, pastagem & Torres et al. (2016) \\
\hline E.camaldulensis $x$ E. grandis & Brasil & Taungya & Arroz, soja & Cacau et al. (2008) \\
\hline $\begin{array}{l}\text { A. mearnsii } \\
\text { A. mangium } \\
\text { E. grandis }\end{array}$ & Brasil & Agrossilviculturais & Diversos agrícolas & Vale et al. (2000) \\
\hline
\end{tabular}

\section{SAFs para produção de energia de biomassa florestal no Brasil}

Os plantios florestais com fins energéticos começaram a surgir no Brasil a partir da década de 1970, quando apareceu o conceito de florestas energéticas, a partir da necessidade de se produzir biomassa florestal em maior escala para atender a indústria de carvão vegetal (Brito, 2013). Em Minas Gerais, diversos projetos e experimentos de florestas energéticas foram desenvolvidos, através de monocultivos adensados de espécies do gênero Eucalyptus em rotações curtas, isto é, ciclos de cortes de 2 a 3 anos, e espaçamentos de 1,0 x 1,5 m; 2,0 x 1,0 m (Couto \& Muller, 2013; Bernstad Saraiva et al., 2017).

Entretanto, estudos têm mostrado que a implantação de monocultivos florestais adensados, cujo objetivo principal é a produção do maior volume de biomassa por unidade de área, em menor espaço de tempo, pode resultar em baixa produtividade, grande mortalidade e gerar impactos negativos sobre a fertilidade do solo e ciclagem de nutrientes (Brito, 2013). Isso ocorre principalmente devido à exportação de uma quantidade considerável de nutrientes do solo, através da retirada contínua de nutrientes na colheita de ciclos curtos, sem a devida reposição, o que favorece diretamente a degradação das propriedades físicas, químicas e biológicas do solo (Berndes et al., 2003).

Em uma revisão de 17 estudos relacionados ao potencial da biomassa florestal para bioenergia, Berndes et al. (2003) observaram que: i) florestas energéticas de larga escala e curta rotação podem gerar degradação ambiental, em função de sua elevada exportação de nutrientes do solo; ii) projetos de recuperação e regeneração de áreas degradadas podem ser feitos através de sistemas agroflorestais, que possuem potencial de recuperação de áreas, se bem manejados; e iii) há um amplo reconhecimento nestes estudos sobre a necessidade de se integrar a produção de bioenergia com programas de alimentação/produção de alimentos e o desenvolvimento rural, o que vai ao encontro de alternativas como os sistemas agroflorestais.

Se por um lado o Brasil é considerado um dos maiores produtores mundiais de madeira para energia, por outro a produção em grande escala sugere algumas questões críticas, uma vez o espaço ocupado pelos monocultivos florestais pode competir tanto com o uso da terra para a produção de alimentos quanto com as florestas nativas. Alternativas para se alcançar melhor distribuição espacial dos meios produtivos incluem a utilização de propriedades florestais produtivas em áreas marginais à agricultura e a implantação de sistemas agroflorestais (Dobie et al., 2015).

Atualmente, a maior parte dos plantios florestais no país destinados á produção de biomassa para energia pertence às siderúrgicas e produtores de carvão vegetal, e seguem práticas de manejo compatíveis com esta finalidade: utilizam espaçamentos mais amplos (3,0 $\mathrm{m} \mathrm{x}$ 2,0 $\mathrm{m}$ a 3,0 $\mathrm{m} \times 3,0 \mathrm{~m}$ ), com ciclos de corte variando de 5 a 7 anos; clones de eucalipto com maior densidade, poder calorífico, e maior teor de lignina em sua composição estrutural (Couto \& Muller, 2013). 
Ainda assim, uma parte considerável da oferta de florestas plantadas de eucalipto e pinus no Brasil é advinda de produtores independentes e fomentados (cerca de $27 \%$ da área total de florestas plantadas no país em 2014, conforme Figura 1), notadamente pequenos e médios proprietários rurais que investem em plantios florestais como fonte de renda a partir da comercialização da madeira in natura (Indústria Brasileira de Árvores, 2015). Muitos desses produtores são fomentados através de incentivos advindos de empresas e do Estado para implantar plantios florestais, recebendo mudas, insumos e algum apoio técnico.

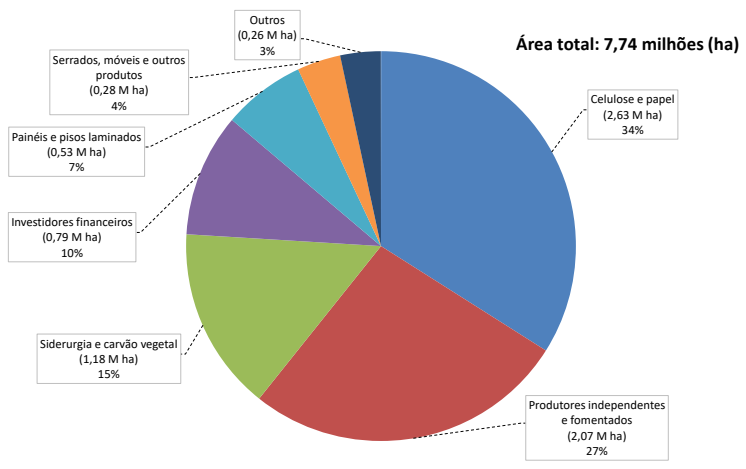

Figura 1. Composição da área de florestas plantadas no país, por segmento (2014). Fonte: Adaptado de Indústria Brasileira de Árvores (2015).

No entanto, esse modelo produtivista de implantação de monocultivos florestais possui gargalos em termos de mercado. O principal deles seriam as oscilações no mercado de madeira para energia, ou, em maior dimensão, a própria crise do setor siderúrgico nacional, que fez reduzir drasticamente a demanda por carvão vegetal criando, consequentemente, uma elevada oferta de madeira no país, o que afetou diretamente os pequenos e médios produtores.

Nesse aspecto, dois programas implantados recentemente pelo Governo Federal buscam incentivar a adoção de Sistemas Agroflorestais: o Programa Nacional de Fortalecimento da Agricultura Familiar (PRONAF), modalidades Floresta e Eco, e o Programa Agricultura de Baixo Carbono (ABC) (Torres et al., 2016). Os sistemas agroflorestais podem servir de alternativa para que pequenos e médios produtores consigam reduzir o risco de mercado e diversificar o fluxo de caixa através da geração de receita com outros produtos.

\section{Práticas de SAFs com fins energéticos no Brasil}

Existem poucos estudos disponíveis na literatura relacionados à implantação de SAFs visando energia de biomassa florestal no Brasil. Os principais estudos denotam que a grande maioria desses SAFs é de modelos agrissilviculturais. Existem algumas instituições que trabalham com pesquisas relacionadas ao potencial de geração de biomassa para energia em SAFs, como a Empresa Brasileira de Pesquisa Agropecuária (Embrapa), a Empresa de Assistência Técnica e Extensão Rural (Emater) e também alguns centros universitários do país.

Rodigheri et al. (2001) desenvolveram estudo como parte do Projeto Madeira do Estado do Paraná, em parceria da Embrapa Florestas com a Emater/PR. O objetivo do estudo foi analisar os custos de produção, produtividade e rentabilidade econômica do cultivo de eucalipto na região norte do Paraná, através dos dados de 42 produtores (pequenos e médios), visando comparar sistemas de monocultivo de eucalipto para energia e serraria, e cultivos consorciados de eucalipto com feijão e milho nas entrelinhas nos primeiros anos da implantação florestal, em Sistema Taungya. Os principais resultados mostraram que a rentabilidade financeira da produção em consórcio (eucalipto, feijão e milho) foi maior do que nos monocultivos, onde o plantio das culturas anuais no primeiro e segundo anos do plantio de eucalipto contribuiu na amortização da implantação florestal, no aumento da produção de alimentos, no uso de mão de obra e no aumento da renda dos produtores. Além disso, a produtividade média do eucalipto manejado para energia e serraria apresentou resultados semelhantes tanto em sistemas consorciados quanto solteiros.

Torres et al. (2016) realizaram estudo pioneiro ao avaliar as propriedades da madeira de eucalipto para fins energéticos em três diferentes SAFs, estimando a densidade básica, o teor de carbono, o poder calorífico e a produção de biomassa seca de madeira das árvores, em Sistemas Agrissilvipastoril e Silvipastoril, em Viçosa, MG. Os três sistemas variaram em espaçamento $-9,0 \mathrm{x}$ $1,0 \mathrm{~m} ; 8,0 \times 3,0 \mathrm{~m} ; 12,0 \times 3,0 \mathrm{~m}$, sendo que o primeiro e o terceiro eram compostos por eucalipto e pasto, e o segundo por feijão, pasto e eucalipto, e também variaram em tratos para adubação. Os autores observaram que: i) os maiores valores médios de densidade básica $\left(\mathrm{g} \mathrm{cm}^{-3}\right)$ 
foram encontrados em sistemas com arranjo espacial mais amplo do eucalipto, demonstrando que o aumento do espaçamento gerou maior densidade básica da madeira; ii) árvores plantadas em espaçamentos mais adensados contavam com menor disponibilidade de recursos para o crescimento e produção de biomassa, em razão da maior competição por água, luz e nutrientes; iii) o teor de carbono da madeira não foi afetado pelo espaçamento e pela associação com as culturas agrícolas e forrageiras; iv) o poder calorífico superior (PCS) foi maior no sistema com espaçamento 9,0 x 1,0 m, apesar de ter sido considerado pelos autores consequente da composição química estrutural do eucalipto (teor de lignina e extrativos), que afeta diretamente o PCS; v) as produções de biomassa seca, carbono e energia disponível foram maiores no primeiro sistema (mais adensado, composto por eucalipto e pasto). Os valores de incremento médio anual (IMA) também foram maiores neste sistema.

Estes resultados ajudam a evidenciar que o maior número de árvores por área e a produtividade volumétrica são fundamentais na análise dos parâmetros energéticos de Sistemas Agroflorestais. Como no sistema 1 (mais adensado) a área útil por árvore era menor, gerou-se maior número de árvores ha ${ }^{-1}$ e produção de maior volume de madeira, contribuindo para o incremento em biomassa seca e, consequentemente, aumentando os demais parâmetros avaliados, tais como a massa de carbono e a energia disponível em GWh ha-1 ano $^{-1}$ (Torres et al., 2016). Nessa análise, no entanto, os próprios autores comentam que é de fundamental importância realizar avaliação técnica e econômica do SAF com fins energéticos, tendo em vista o preço da madeira para energia, o preço da madeira para outros usos, e o custo de oportunidade de se ter maior biomassa florestal em detrimento da produção agrícola e/ou pastagem, podendo-se utilizar o índice de equivalência de área e de avaliação econômica.

As principais espécies arbóreas utilizadas no país na composição dos SAFs com fins energéticos são do gênero Eucalyptus, em razão de seus altos índices de produtividade, adaptação a diferentes condições ecológicas, usos para os mais variados fins e, principalmente, características energéticas (densidade da madeira e poder calorífico), aliados ao conhecimento silvicultural e genético adquirido nas últimas décadas (Oliveira Neto et al., 2007; Couto \& Muller, 2013). O gênero Acacia também possui relevância no país, principalmente na região sul, com a espécie A. mearnsii, que possui poder calorífico próximo a $4.800 \mathrm{kcal} \mathrm{kg}^{-1}$, e elevada densidade (em torno de $0,7 \mathrm{a} 0,85$ $\mathrm{g} \mathrm{cm}^{-3}$ ), e $A$. mangium, com poder calorífico próximo a $4.600 \mathrm{kcal} \mathrm{kg}^{-1}$. Comparando-se os dois gêneros, com as espécies E. grandis e A. mangium, Vale et al. (2000) demonstraram que, embora tenham poder calorífico parecidos, a quantidade de energia disponibilizada na forma de calor do fuste de $E$. grandis foi superior a de $A$. mangium (222.085,31 kcal árvore ${ }^{-1} \mathrm{e}$ $91.285,62 \mathrm{kcal}^{\text {árvore }}{ }^{-1}$, respectivamente), tendo em vista sua maior produção de matéria seca.

Outros estudos, principalmente da Embrapa, avaliaram algumas espécies arbóreas para produção de energia em plantios homogêneos e sistemas agroflorestais na Amazônia. Foram analisadas as espécies A. auriculiformis, A. mangium, Sclerobium paniculatum, G. sepium, L. leucocephala, Sesbania formosa e E. urophylla para produção de energia, nos municípios de Iranduba e Manacapuru, maior polo oleiro e consumidor de lenha do Estado do Amazonas. As espécies que se destacaram com características potenciais para produção de lenha foram A. mangium e A. auriculiformis, por apresentarem rápido crescimento, alto incremento médio anual, alta produção de biomassa, elevado poder calorífico e alta densidade básica (Neves et al., 1994; Azevedo et al., 2002; Souza et al., 2008).

Alguns outros projetos no país buscam avaliar a integração da produção de matéria prima para biodiesel e biomassa lenhosa para energia. Em um programa desenvolvido pela Embrapa denominado Projeto MACSAF, tem-se como objetivo a produção de macaúba em sistemas agroflorestais para gerar alimentos e matéria prima para bioenergia, em consórcio com espécies arbóreas com potencial para energia ou múltiplos usos. Considera-se que a produtividade de óleo da macaúba é próxima à do dendê, outra espécie bastante utilizada para bioenergia. A iniciativa faz parte do Programa para Desenvolvimento de Cultivos Alternativos para Biocombustíveis do World Agroforestry Centre, e os principais resultados ainda devem ser divulgados (Laviola et al., 2016).

Um dos poucos estudos que abordaram com maior ênfase os tratos silviculturais em SAFs para energia foi realizado por Cacau et al. (2008), para avaliar o uso de decepa de plantas jovens de eucalipto para a produção de árvores de menor diâmetro em sistemas agroflorestais, com colheita facilitada por pequenos produtores; e 
também para a recuperação de povoamentos jovens severamente danificados e produção de biomassa para energia (carvão vegetal), em ciclos curtos. O estudo foi realizado em um povoamento de E. camaldulensis $\mathrm{x} E$. grandis, estabelecido em espaçamento $9,5 \mathrm{~m} \mathrm{x}$ 4,0 m, em Vazante, MG, com associação dos componentes agrícolas arroz e soja, em 2004. As tendências de crescimento observadas indicaram que a decepa de plantas jovens pode ser utilizada para a produção de madeira de dimensões reduzidas, em espaçamentos amplos em sistemas agroflorestais, viabilizando a produção de biomassa para energia em rotações menores. Além disso, também observaram que a decepa de plantas jovens pode ser usada no manejo da cultura do eucalipto para a recuperação de povoamentos jovens danificados por pragas, doenças, estresse hídrico, geada, entre outros.

Com o manejo adequado da brotação, essa técnica silvicultural pode ser uma ferramenta alternativa para os pequenos produtores rurais, interessados em produzir madeira para carvão vegetal em SAF, e que muitas vezes não possuem máquinas e equipamentos para manipular toras de grandes dimensões. Além disso, as curtas rotações, de quatro a seis anos, podem servir para possível antecipação de receitas.

\section{Considerações finais}

Diversas espécies arbóreas, arranjos de componentes e tipos de SAFs ao redor do mundo sugerem potencial para se produzir madeira com qualidade para energia, atendendo propriedades essenciais ao uso energético, com escala para o abastecimento do produtor rural e para venda em comércios e indústrias locais. Entretanto, esse potencial depende de diversas condições socioeconômicas e ambientais, tais como: estruturação de mercado para biomassa florestal; competição da biomassa por outros usos; objetivo de produção predominante do SAF; condições ambientais; produtividade da espécie arbórea; manejo agroflorestal; fatores socioeconômicos; infraestrutura e distribuição/ logística; políticas e legislação.

No que tange ao objetivo de produção do sistema agroflorestal, observou-se que, em sistemas onde o foco principal é a produção de madeira (para energia ou outros usos) a escala para biomassa energética provavelmente será maior e, portanto, haverá maior potencial para este uso. Por outro lado, sistemas que incluem pastagem e/ou animais de maneira permanente, normalmente, apresentam menor oferta de madeira e menor escala para biomassa.

As práticas agrossilviculturais para produção de madeira para energia são bastante comuns em países da Europa, Ásia, África e Américas Central e do Norte. A depender do grau de desenvolvimento econômico e de fatores culturais e de mercado, a produção de biomassa florestal pode ter como finalidade principal o uso energético na forma de lenha, cavaco, carvão vegetal e de resíduos, ou visar múltiplos usos, abrangendo uma ampla variedade de espécies e arranjos.

Em países desenvolvidos, os estudos não só costumam analisar o potencial de espécies e práticas agroflorestais, como também as tecnologias e inovações para a disseminação de SAFs. Em países subdesenvolvidos (e em desenvolvimento), onde há maior dependência da madeira para energia, muitos estudos buscam entender formas de produção de madeira que consigam aliar a sustentabilidade do meio rural com o aumento da oferta de biomassa para energia. Ao mesmo tempo, muitos destes estudos alertam que as proposições realizadas por instituições e agências governamentais já deveriam buscar a adequação destes sistemas à realidade local.

Embora ainda pouco incentivado, a implantação de SAFs no Brasil visando biomassa florestal para energia também apresenta potencial técnico e econômico, com alguns estudos sendo liderados por instituições públicas de apoio ao produtor rural. Com base no crescimento dos plantios florestais e nos avanços tecnológicos alcançados no campo da silvicultura, o maior incentivo à adoção de práticas agroflorestais que visem a produção de biomassa para energia pode servir de alternativa aos pequenos e médios produtores rurais, possibilitando redução dos riscos às oscilações de mercado, principalmente em períodos de crise das commodities agroflorestais. Adicionalmente, por ser o maior produtor de carvão vegetal no mundo, sendo grande consumidor de madeira para o uso energético, existe potencial no Brasil para ampliar a inserção de sistemas com esse propósito.

\section{Necessidades de pesquisas futuras}

Os estudos relacionados aos $\mathrm{SAFs}$ com fins energéticos ainda carecem de investigações e aprofundamentos em vários pontos críticos. Podem-se citar como principais questões: i) necessidade de novos estudos sobre espécies florestais com potencial energético, e que também se insiram na realidade cultural com aceitação de mercado em diferentes regiões; ii) tecnologias de implantação 
e colheita agroflorestal que possam ser levadas ao pequeno e médio produtor rural, principalmente em regiões menos capitalizadas; iii) estudos relacionados ao comportamento dos componentes arbóreo, agrícola e pecuário dos sistemas; iv) novas pesquisas para o desenvolvimento de equipamentos e tecnologias de queima e conversão energética que possam ser levadas às regiões menos desenvolvidas; v) técnicas silviculturais que beneficiem o pequeno e médio produtor interessado na produção de madeira para energia; vi) pesquisas com ênfase nas propriedades da madeira para energia, o que é de suma importância para se buscar qualidade do insumo, melhorar a eficiência da queima e possivelmente reduzir os custos; vii) estudos da viabilidade econômica desses sistemas.

\section{Referências}

AgroForstEnergie. Economic and ecological evaluation of agroforestry systems in farming practice. 2015. Disponível em: $<$ http://www.agroforstenergie.de/en/>. Acesso em: 9 maio 2016.

Arco-Verde, M. F. et al. Aporte de nutrientes e produtividade de espécies arbóreas e de cultivos agrícolas em sistemas agroflorestais na amazônia. Floresta , v. 39, n. 1, p. 11-22, 2009. DOI: 10.5380/ rf.v39i1.13721.

Azevedo, C. P. et al. Produção de lenha na região de Iranduba e Manacapuru -Amazonas: Acacia mangium e Acacia auriculiformis. Manaus: Embrapa Amazônia Ocidental, 2002. 4 p. (Embrapa Amazônia Ocidental. Circular técnica, 16).

Berndes, G. et al. The contribution of biomass in the future global energy supply: a review of 17 studies. Biomass and Bioenergy. v. 25, n. 1, p. 1-28, 2003. DOI: 10.1016/S0961-9534(02)00185-X.

Bernstad Saraiva, A. et al. Provision of pulpwood and short rotation eucalyptus in Bahia, Brazil: environmental impacts based on lifecycle assessment methodology. Biomass and Bioenergy, v. 105, p. 41-50, 2017. DOI: 10.1016/j.biombioe.2017.06.004.

Brito, J. O. \& Cintra, T. C. Madeira para energia no Brasil: realidade, visão estratégica e demandas de ações. Biomassa e Energia, v. 1, n. 2, p. 157-163, 2004.

Brito, J. O. Energia da Madeira. In: Santos, F. (Org). Bioenergia e biorrefinaria: cana-de-açúcar e espécies florestais. Viçosa, MG, 2013, p. 271-295.

Cacau, F. V et al. Decepa de plantas jovens de eucalipto e manejo de brotações, em um sistema agroflorestal. Pesquisa Agropecuária Brasileira, v. 43, n. 11, p. 1457-1465, 2008.

Couto, L. \& Müller, M. D. Produção de florestas energéticas. In: Santos, F. (Org). Bioenergia e Biorrefinaria: cana-de-açúcar e espécies florestais. Viçosa, MG, 2013. p. 298-319.
Dobie, P. et al. Strategy on tree-based energy: clean and sustainable energy for improving the livelihoods of poor people. Nairobi, Kenya: World Agroforestry Centre, 2015.36 p. Disponível em: $<$ http://www. worldagroforestry.org/downloads/Publications/PDFS/RP15690. pdf>. Acesso em: 30 mar. 2016.

Dobie, P. \& Sharma, N. Trees as a global source of energy: from fuelwood and charcoal to pyrolysis-driven electricity generation and biofuels. [Nairobi, Kenya]: World Agroforestry Center, 2014. Disponível em: < http://www.worldagroforestry.org/sites/default/ files/Dobie $\% 20 \& \% 20$ Sharma $\% 202014 \% 20-\% 20$ Trees $\% 20$ as $\% 20$ a\%20Global\%20Source\%20of\%20Energy,\%20WCA\%202014.pdf $>$. Acesso em: 25 abr. 2016.

Empresa de Pesquisa Energética (Brasil). Balanço Energético Nacional 2015: ano base 2014. Rio de Janeiro, 2015. 292 p. Disponível em: $<$ https://ben.epe.gov.br/downloads/Relatorio_Final_ BEN_2015.pdf>. Acesso em: 25 abr. 2016.

FAO. Forest and energy in OECD Countries. Rome, 2008. 128 p.

FAO. State of World's Forests 2011. Rome, 2011, 164 p. Disponível em: < http://www.fao.org/docrep/013/i2000e/i2000e.pdf>. Acesso em: 30 mar. 2016.

Giwa, A. et al. A comprehensive review on biomass and solar energy for sustainable energy generation in Nigeria. Renewable and Sustainable Energy Reviews, v. 69, p. 620-641, 2017. DOI: 10.1016/j.rser.2016.11.160.

Gregerson, H. et al. People and trees: the role of social forestry in sustainable development. Washington, D.C.: World Bank, 1989. $273 \mathrm{p}$.

Gruenewald, H. et al. Agroforestry systems for the production of woody biomass for energy transformation purposes. Ecological Engeneering, v. 29, n. 4, p. 319-328, 2007. DOI: 10.1016/j. ecoleng.2006.09.012.

Indústria Brasileira da Árvore. IBÁ: Indústria Brasileira da Árvore. Brasília, DF, 2015. 80 p. Relatório Ibá 2015. Disponível em: <http:// iba.org/images/shared/iba_2015.pdf>. Acesso em: 20 abr. 2016.

Jensen, M. Woodfuel productivity of agroforestry systems in Asia. Bankok: FAO, 1995. 40 p. (FAO. Field document, 45)

Kalame, F. et al. Modified taungya system in Ghan: a win win practice for forestry and adaptation to climate change? Environmental Science \& Policy, v. 14, n.5, p. 519-530. 2011. DOI: 10.1016/j.envsci.2011.03.011.

Kalu, C. et al. Economic potential of Taungya Farming System in Edo State, Nigeria. Journal of Agriculture and Social Research, v. 11, n. 1, 2011.

Kerkhof, P. Agroforestry in Africa: a survey of project experience. Londres: Panos Institute, 1990. 216 p.

Kursten E. Fuelwood production in agroforestry systems for sustainable land use and $\mathrm{CO}_{2}$-mitigation. Ecological Engeneering, v. 16, n. supl. 1, p. 69-72, 2000. DOI: 10.1016/S0925-8574(00)00054-9.

Mercer, D. E. \& Soussan, J. Fuelwood: an analysis of problems and solutions for less developed countries. In: Sharma, N. P. (Ed.). Managing the world's resources. Washington, D.C.: World Bank, 1992. p. 177-213. 
Mirck, J. \& Quinkenstein, A. Research and development protocol for alley cropping in Germany. [S.1.]: Agforward, 2015. 10 p.

Montes, E. C. et al. Growth and fuelwood properties of five tree and shrub species in the Sahelian and Sudanian ecozones of Mali: relationships with mean annual rainfall and geographical coordinates. New Forests, v. 45, n. 2, p. 179-197, 2014. DOI: 10.1007/s11056013-9401-9.

Munslow, B. et al. The Fuelwood trap: a study of the SADCC Region. Londres: SADCC Energy Secretariat, 2012. 160 p.

Nair, P. K. R. An introduction to agroforestry. Dordrecht: Kluwer, 1993. 499 p.

Nair, P. K. R. et al. Soil carbon sequestration in tropical agroforestry systems: a feasibility appraisal. Environmental Science \& Policy, v. 12, n. 8, p. 1099-1111, 2009. DOI: 10.1016/j.envsci.2009.01.010.

Ndayambaje, J. D. \& Mohren, G. M. J. Fuelwood demand and supply in Rwanda and the role of Agroforestry. Agroforestry Systems, v. 83, n. 3, p. 303-320, 2011. DOI: 10.1007/s10457-011-9391-6.

Negash, M. \& Kanninen, M. Modeling biomass and soil carbon sequestration of indigenous agroforestry systems using CO2FIX approach. Agriculture, Ecosystems \& Environment, v. 203, p. 147-155, 2015. DOI: 10.1016/j.agee.2015.02.004.

Oliveira Neto, S. N et al. Eucalipto: as questões ambientais e seu potencial para sistemas agrossilvipastoris. In: Fernandes, E. N. et al. (Ed.). Sistemas agrossilvipastoris na América do Sul: desafios e potencialidades. Juiz de Fora: Embrapa Gado de Leite, 2007. p. 245-282.

Oliveira Neto, S. N. et al. Sistemas agroflorestais para adequação ambiental de propriedades rurais. Informe Agropecuário, v. 33, n. 271, p. 70-77, 2012.

Payn, T. et al. Changes in planted forests and future global implications. Forest Ecology and Management, v. 352, p. 57-67. 2015. DOI: 10.1016/j.foreco.2015.06.021.

Platen, H. V. Alternativas de reforestación: Taungya y sistemas agrosilviculturales permanentes vs. Plantaciones puras: la economía. Turrialba: CATIE, 1996. 25 p. (CATIE. Serie técnica. Informe técnico, 250).

Portilla, W. \& Mckenzie, T. A. Un caso de evolution en el desarollo de proyectos forestales. Silvoenergia, n. 40, p. 4, 1991.

Redhead, J. F. \& Maghembe, J. A. Agroforestry: preliminary results of intercropping Acacia, Eucalyptus and Leucaena with maize and beans. In: SYMPOSIUM OF INTERCROPPING IN SEMI-ARID AREAS, 2., 1980, Morogon, Tanzania. Intercropping: proceedings. Ottawa: IDRC, 1982. p. 43-49.

Ribeiro G. B. D. \& Valverde S. R. Breve elucidação sobre os leilões de energia e o potencial da biomassa florestal. Revista Madeira, Palmas, p. 43-45, 2016. Disponível em: < https://issuu.com/ abaf_2014/docs/revista-madeira-2016>. Acesso em: 20 ago. 2016
Rigueiro-Rodríguez, A. et al (Ed.). Agroforestry in Europe: current status and future prospects. [S.1.]: Springer, 2009. 450 p. (Advances in agroforestry, 6).

Rodigheri, H. R. et al. Custo de produção, produtividade e renda do eucalipto conduzido para uso múltiplo no norte pioneiro do Estado do Paraná. Colombo: Embrapa Florestas, 2001. 12 p. (Embrapa Florestas. Circular técnica, 51).

Santos, M. J. C. \& Paiva, S. N. Os sistemas agroflorestais como alternativa econômica em pequenas propriedades rurais: estudo de caso. Ciência Florestal, v. 12, n. 1, p. 135-141, 2002. DOI: $10.5902 / 198050981707$.

Schlönvoigt, M. \& Beer, J. Initial growth of pioneer timber tree species in a Taungya system in the humid lowlands of Costa Rica. Agroforestry Systems, v. 51, n. 2, p. 97-108, 2001. DOI: 10.1023/A:1010674402907.

Souza, C. R. et al. Espécies florestais para produção de energia. Manaus: Embrapa Amazônia Ocidental, 2008. 8 p. (Embrapa Amazônia Ocidental. Circular técnica, 31).

Torres, C. M. et al. Estimativas da produção e propriedades da madeira de eucalipto em Sistemas Agroflorestais. Scientia Florestalis, v. 44, n.109, p. 137-148, 2016. DOI: 10.18671/scifor.v44n109.13.

USDA National Agroforestry Center. Agroforestry: working trees for energy. Lincoln, 2012. Disponível em: $<$ nac.unl.edu/documents/ workingtrees/brochures/wt4energy.pdf > . Acesso em: 15 maio. 2016.

Vale, A. T. et al. Produção de energia do fuste de Eucalyptus grandis hill ex-maiden e Acacia mangium Willd em diferentes níveis de adubação. Cerne, v. 6, n. 1, p. 83-88, 2000.

Valverde, S. R. et al. Silvicultura brasileira: oportunidades e desafios da economia verde. Rio de Janeiro: Fundação Brasileira para o Desenvolvimento Sustentável, 2012.39 p. (Coleção de estudos sobre diretrizes para uma economia verde no Brasil). Disponível em: <http://www.fbds.org.br/IMG/pdf/doc-29.pdf $>$. Acesso em: 15 abr. 2016

Vidal, A. \& Hora, A. da. Perspectivas do setor de biomassa de madeira para a geração de energia. BNDES Setorial: Papel e Celulose, v. 33, p. 261-314, 2010. Disponível em: <https://web.bndes.gov.br/bib/ jspui/bitstream/1408/2523/1/A\%20BS\%2033\%20Perspectivas $\% 20$ do $\% 20$ setor $\% 20$ de $\% 20$ biomassa $\% 20$ de $\% 20$ madeira $\% 20$ para $\% 20$ a\%20gera $\%$ c3\%a7\%c3\%a3o\%20de\%20energia_P.pdf>. Acesso em: 20 abr. 2016

Vital, R. B. et al. Qualidade da madeira para fins energéticos. In: Santos, F. et al. (Ed.). Bioenergia e biorrefinaria: cana-de-açúcar e espécies florestais. Viçosa, MG, 2013. p. 322-354.

Zhang, D. et al. Policy instruments for developing planted forests: theory and practices in China, the U.S., Brazil, and France. Journal of Forest Economics, v. 21, n. 4, p. 223-237, 2015. DOI: 10.1016/j. jfe.2015.09.004. 